\title{
Esophageal cancer stem cells and implications for future therapeutics
}

This article was published in the following Dove Press journal:

OncoTargets and Therapy

19 April 2016

Number of times this article has been viewed

\section{Xia Qian* \\ Cheng Tan* \\ Feng Wang* \\ Baixia Yang \\ Yangyang $\mathrm{Ge}$ \\ Zhifeng Guan \\ Jing Cai}

Department of Radiation Oncology, Nantong Tumor Hospital, Affiliated

Tumor Hospital of Nantong

University, Nantong, People's

Republic of China

*These authors contributed equally to this work
Correspondence: Jing Cai

Department of Radiation Oncology,

Nantong Tumor Hospital, Affiliated

Tumor Hospital of Nantong University,

Tong Yang Road, No 30, Nantong

226321, People's Republic of China

Tel +8613706299417

Fax +86 5I3 8657 I20I

Email cj7227@sina.com

\begin{abstract}
Esophageal carcinoma (EC) is a lethal disease with high morbidity and mortality worldwide, and the incidence has been increasing in recent years. Although the diagnosis and treatment of EC have improved considerably, EC has rapidly progressed in the clinical setting and has a poor prognosis for its metastasis and recurrence. The general idea of cancer stem cells (CSCs) is primarily based on clinical and experimental observations, indicating the existence of a subpopulation of cells that can self-renew and differentiate. The EC stem cells, which can be isolated from normal pluripotent stem cells by applying similar biomarkers, may participate in promoting esophageal tumorigenesis through renewal and repair. In this review, major emphasis is given to CSC markers, altered CSC-specific pathways, and molecular targeting agents currently available to target CSCs of esophageal cancer. The roles of numerous markers (CD44, aldehyde dehydrogenase, CD133, and ATP-binding cassette subfamily G member 2) and developmental signaling pathways (Wnt/ $\beta$-catenin, Notch, hedgehog, and Hippo) in isolating esophageal CSCs are discussed in detail. Targeting CSCs can be a logical strategy to treat EC, as these cells are responsible for carcinoma recurrence and chemoradiation resistance.
\end{abstract}

Keywords: esophageal cancer, cancer stem cells, CD44, ALDH, CD133, ABCG2

\section{Introduction}

Esophageal carcinoma (EC) is one of the most common malignancies worldwide. EC can be classified into two major pathological subtypes: esophageal adenocarcinomas (EACs) and esophageal squamous cell carcinomas (ESCCs). The incidence of EC has obvious regional characteristics. The prevalence of EC in Asian countries is mainly due to the increasing trend of established risk factors such as diet, alcohol, tobacco chewing, smoking, and physical inactivity. Smoking is a well-known risk factor for ESCC. ${ }^{1}$ The People's Republic of China has a high incidence of EC, where $~ 90 \%$ of all cases are ESCCs, and the annual incidence and deaths in the People's Republic of China account for $52.5 \%$ and $41.8 \%$ of those throughout the world, respectively. ${ }^{2}$ No efficacious treatment is currently available to cure this disease. The overall 5 -year survival rate still varies from $15 \%$ to $25 \%{ }^{3}$ Several studies have shown that $70 \%$ of patients already suffer from cancer metastases, with a cervical lymph node metastatic rate ranging from $73.0 \%$ to $74.5 \%$ when dysphagia was first presented, which is the main clinical symptom of EC. ${ }^{4}$ The most important reasons for poor EC prognosis are delayed diagnosis, metastasis, high relapse rate, and a poor knowledge of the cellular and molecular mechanisms underlying the initiation, promotion, and progression of EC. Recent studies have shown that many solid tumors contain a cell subpopulation known as cancer stem cells (CSCs). ${ }^{5,6} \mathrm{CSCs}$, which are present in many cancers, are thought to lead to aggressive tumor behavior and have exceedingly high 
tumor-initiating capacity. Several features of CSCs are as follows: ${ }^{7,8}$ 1) self-renewal ability: CSCs can produce progeny cells similar to the last generation, thereby maintaining continuous growth; 2) differentiation potential: new tumors that can be formed consist of differentiated CSCs in vitro; 3) high tumorigenicity: a tumor can develop in an animal experiment when a few CSCs are injected into animals in vivo; and 4) therapy resistance: the ATP-binding cassette (ABC) membrane transport proteins of CSCs can intake and excrete a wide variety of substances associated with cellular energy metabolism, resulting in resistance to many anticancer drugs. CSCs can be distinguished from normal stem cells in that they have tumorigenic activity. ${ }^{4}$ Much effort has been invested recently on characterizing and identifying CSCs in various types of cancers and the major mechanisms involved in controlling their unique behavior. $\mathrm{CSCs}$, which are involved in regulating the $\mathrm{Wnt} / \beta$-catenin, Notch, hedgehog $(\mathrm{Hh})$, and Hippo signaling pathways in EC, may be particularly tolerant to radiotherapy and chemotherapy, thereby leading to recurrence, metastasis, and insufficient response to conventional therapies..$^{9,10}$ Therefore, various stem cell markers that are enriched in EC must be determined to isolate cells with stem-like characteristics. Understanding the different signaling pathways related to the regulation and maintenance of esophageal carcinoma stem cells (ECSCs) is necessary. The critical pathways associated with such activities are promising targets for therapeutics. Although the significance of CSCs in EC development and progression is quite evident, no precise details are available. This review is aimed at summarizing the relationship between EC and CSCs. A better understanding of the different markers used to identify and characterize ECSCs, as well as the signaling mechanisms, can aid in the development of more effective therapeutics in the treatment of EC and prevention of relapse.

\section{Esophageal carcinoma stem cells}

In recent decades, many studies and clinical trials have shown that CSCs exist in certain types of tumors, such as acute myelogenous leukemia, ${ }^{11}$ head and neck squamous cell carcinoma, ${ }^{12}$ breast cancer, ${ }^{13}$ and so on. ${ }^{14,15}$ In light of these studies, the unlimited proliferation and metastasis of malignant cells are likely to be managed and driven by such CSCs. Nowadays, several researchers have shown that the existence of CSCs can lead to therapeutic failure of ESCC. ${ }^{16}$ Dysregulation of CSC signaling such as the Hippo/Yes-associated protein 1 (YAP-1), Wnt/ $\beta$-catenin, and $\mathrm{Hh}$ has been implicated in tumor maintenance and in conferring therapy resistance. ${ }^{17,18}$ These pathways are also involved in the development of EC in adults because of genetic alterations that result in esophageal oncogenesis from the imbalance between differentiation and self-renewal. ${ }^{19}$ The presence of cell-surface markers such as cluster of differentiation (CD)271 and CD90 on the CSCs has been routinely exploited to isolate cell subpopulations from the pool of cancer cells with stemness properties such as enhanced tumor-initiating capacity, increased recurrence rate, and increased resistance to therapy. ${ }^{20,21}$ In a recent report, cells expressing high $\alpha 6$ integrin and low CD71 levels, termed $\alpha 6^{\text {bri }} \mathrm{CD} 71^{\mathrm{dim}}$, were shown to be a minor subpopulation of small and undifferentiated cells that represent a putative CSC population, by a combination of cell kinetic studies and cellsurface markers. ${ }^{22}$ According to another study, transforming acidic coiled-coil protein 3 (TACC3) can be used to identify whether TACC3 can serve as a biomarker for the diagnosis and prognosis of ESCC, which can form spheres and show resistance against multiple drugs in vitro. ${ }^{23}$ In addition, the stem cell marker leucine-rich G-protein coupled receptor 5 (LgR5) is expressed in EAC, irrespective of its association with Barrett's esophagus, and appears to have a negative influence on survival. However, further investigations are required to substantiate these findings. ${ }^{24}$ Therefore, a thorough analysis of various esophageal CSC-associated markers is crucial to appreciate their potential fully before putting them into application.

\section{Markers used in the identification of ECSCs}

As a large number of CSC markers have recently become available in the literature, only very few are eventually validated. However, the notable variation makes it possible to identify the different CSCs from other cancer cells from the elaborate studies performed within this area. Different surface markers are simultaneously expressed in CSCs, and the use of a single marker may not be sufficient to isolate a pure subpopulation of stem-like cells from the pool of cancer cells. ${ }^{25}$ Consequently, studying the available CSC markers is urgently needed in relation to $\mathrm{EC}$, and such markers may ameliorate the prognosis and overall therapeutic intervention for this type of cancer. In the following paragraphs, we discuss in detail the present knowledge about the ECSC markers CD44 and CD24, ABC subfamily G member 2 (ABCG2), CD133-C-X-C chemokine receptor type 4 (CXCR4), and aldehyde dehydrogenase (ALDH), since they are the most popular molecules in EC research (Table 1). 
Table I Cell-surface markers in cell lines of EC

\begin{tabular}{|c|c|}
\hline Cell markers & EC cell lines \\
\hline CD27I & $\mathrm{KYSEs}^{20}$ \\
\hline CD90 & $\begin{array}{l}\text { ECI8, ECI09, HKESCI, KYSE } 30, \text { KYSEI } 40 \text {, } \\
\text { KYSEI } 80, \text { KYSE4I0, KYSE5I0, and KYSE52021 }\end{array}$ \\
\hline$\alpha 6^{\text {bri CD7 Idim }}$ & The mouse esophagus cells ${ }^{22}$ \\
\hline TACC3 & $\begin{array}{l}\text { Eca-109, ECI8, HKESCI, KYSE } 30, \text { KYSEI } 40 \text {, } \\
\text { KYSEI } 50, \text { KYSE4I } 0 \text {, and KYSE5 I } 0^{23}\end{array}$ \\
\hline LgR5 & OE-3324 \\
\hline CD44 & YES-2 $2^{28}$ \\
\hline CD44+/CD24- & $\mathrm{OE}-33$ and $\mathrm{OE}-2 \mathrm{I}^{29}$ \\
\hline ICAMI and CD44 & CE8IT/VGH, CEI46T/VGH ${ }^{30}$ \\
\hline $\mathrm{ABCG} 2$ & $\mathrm{NCl}-\mathrm{SB}-\mathrm{Es} \mathrm{Cl}$ and $\mathrm{NCl}-\mathrm{SB}-\mathrm{EsC2}^{34}$ \\
\hline CXCR4+ & TE-I ${ }^{40}$ \\
\hline ALDHI & $\mathrm{ECl} 09^{46-49}$ \\
\hline
\end{tabular}

Abbreviations: EC, esophageal carcinoma; CD, cluster of differentiation; TACC3 transforming acidic coiled-coil protein 3; LgR5, leucine-rich G-protein coupled receptor 5; ICAMI, intercellular adhesion molecule I;ABCG2, ATP-binding cassette subfamily G member 2; ALDHI, aldehyde dehydrogenase I; CXCR4, C-X-C chemokine receptor type 4 .

\section{CD44 and CD24}

CD44 is an extensively distributed cell-surface transmembrane protein that belongs to the adhesion molecule superfamily. Based on the special link between cells and the matrix, CD44 plays a supporting role in tissue development, inflammation, wound healing, and many other pathophysiological processes. CD44 has a close relationship with cell motility, tumorigenesis, invasion, and metastasis, and it has received universal attention in the study of gastrointestinal cancer. CD44, which greatly influences tumor initiation and progression, is still considered an important biomarker for CSCs in ESCCs despite being expressed by the majority of ESCCs. ${ }^{26}$ Another stem cell-surface marker called CD24 is a heat-stable antigen that is expressed in many cancers. CD24 is a central marker for the diagnosis and prognosis of tumorigenesis because of its positive influence on cellmatrix and cell-cell interactions; thus, CD24 is involved in cell adhesion and migration. ${ }^{27}$ Almanaa et a ${ }^{28}$ isolated CSCs from a human EC cell YES-2 parental line using standard Aldefluor flow cytometry and then created a cell line enriched in CSCs (YES-2CSC). It showed that in YES-2CSC cells, CD44 levels are higher than in YES-2 cells, suggesting that CD44 may be one of the CSC markers in EC. According to current knowledge, the CD44+/CD24- subpopulation of EC cells exerts a higher proliferation rate and sphere-forming potential and is more tolerant to radiation in vitro than unselected or CD44+/CD24+ cells. Furthermore, CD44+/ CD24- cells rapidly form xenograft tumors and are often deposited in hypoxic tumor areas. Based on current data and evidence from other groups, CD44+/CD24- may be an esophageal tumor stem-like cell marker. ${ }^{29}$ In addition, a study has reported that the intercellular adhesion molecule 1 and CD44 could have a compensatory effect on maintaining the stemness characteristics of ESCCs, suggesting that the combination of multitargeting therapies should be seriously considered to acquire a more potent therapeutic effect on CSCs of $\mathrm{ESCCs}^{30}$ Furthermore, Honing et $\mathrm{al}^{31}$ found that $\mathrm{CD} 44$, sonic $\mathrm{Hh}$, and sex-determining region Y-box 2 (SOX2) are associated with systemic recurrence and a poor survival outcome in esophageal cancer patients treated with neoadjuvant chemoradiotherapy.

\section{ATP-binding cassette subfamily $G$ member 2}

Another important marker used in identifying ECSC is the $\mathrm{ABC}$ reporter. $\mathrm{ABCG} 2$, the second member of group $\mathrm{G}$ in the $\mathrm{ABC}$ family, is abundantly expressed in all kinds of cells, including placental trophoblast cells, intestinal epithelial cells, and hepatic tubule membrane and brain microvascular endothelial cells. Moreover, ABCG2 expression plays a role in the proliferation, initiation, and promotion of tumor cell development. ${ }^{32}$ V-ATPase, a kind of ATPase produced on the microsomes and presented on the cell membrane, is related to therapy resistance because of changes in intracellular and extracellular $\mathrm{pH}$ and environment. Huang et $\mathrm{a}^{33}$ sought to determine the role of ABCG2/V-ATPase in ESCC cells and observed that both ABCG2 and V-ATPase are highly expressed. ABCG2/V-ATPase expression and staining intensity are positively correlated with the pathological grade. In addition, ABCG2/V-ATPase expression may result in cell invasion, metastasis, and drug tolerance of EC. Exposure of EC cells to cigarette smoke condensate leads to upregulation of the xenobiotic pump ABCG2 and confers treatment resistance in EC. ${ }^{34}$ These results show that $\mathrm{ABCG} 2$ is indeed related to the ECSC phenotype.

\section{CDI33 and CXCR4}

CD133 and CXCR4 are frequently adopted markers for detecting and isolating CSCs. CD133 is a kind of 5-transmembrane glycoprotein and a CSC marker in the esophagus, brain, colon, pancreas, prostate, liver, lung, and kidney. ${ }^{14-16,35-37} \mathrm{CXCR} 4$, a membrane-bound receptor, selectively binds to the CXC chemokine ligand 12 , which is also named "stromal cell-derived factor 1". The CXC chemokine ligand 12/CXCR4 signaling pathway is closely related to carcinogenesis, progression, and metastasis, resulting in low overall survival and poor prognosis. ${ }^{38,39}$ In a study 
involving 154 tissues of ESCC patients and ESCC cell line TE-1, immunohistochemical staining and flow cytometry were performed to examine CD133 and CXCR4 expression in tissues and TE-1. The concomitant expression of CD133 and CXCR4 was up to $20.78 \%$ among 154 patient tissues. In cultured cells, CXCR4+ cells (CD133+CXCR4+ and CD133-CXCR4+) showed high invasive capacity. Furthermore, CD133+CXCR4+ cells displayed high proliferative and metastatic potential. Patients who synergistically expressed high CD133-CXCR4 had remarkably decreased diseasefree survival and overall survival. These findings proved that concomitant high CD133-CXCR4 expression may be a novel marker for prognosis assessment and may be useful as a potential therapeutic target for ESCC patients. ${ }^{40}$ These results were consistent with the findings of other studies. ${ }^{39,41}$

\section{ALDH}

ALDH1A1, a predominant isoform of ALDH family in the cytoplasm of mammals, ${ }^{42}$ is usually regarded as a marker for normal hematopoietic progenitor cells. ${ }^{43}$ It also appears in several malignant tumors with stem cell features, including leukemia, breast cancer, and lung cancer. ${ }^{44,45}$ Wang et $\mathrm{al}^{46}$ reported that ALDH1A1 is mainly expressed in the nuclei of ESCCs and associated with EC tumorigenesis and invasion. The expression of ALDH1A1 was recently found to be significantly increased in tumor spheres ${ }^{47}$ and $3 \mathrm{D}$ cultured cancer stem-like cells ${ }^{48}$ of ESCCs. This finding suggested that ALDH1A1 may be a good biomarker for the CSCs of ESCCs. Yang et $\mathrm{al}^{49}$ found that isolated cancer stem-like cells from an ESCC cell line EC109 depended on ALDH1A1 and that those cells that express ALDH1A1 ${ }^{\text {high }}$ possessed stronger ability of self-renewal, repair, and tumorigenesis, indicating stem-cell properties. The degree of malignancy in cells was compared between ALDH1A1 $1^{\text {high }}$ cells and ALDH1A1 $1^{\text {low }}$ cells to further verify their stemness. ALDH1A1 ${ }^{\text {high }}$ ESCCs express increased vimentin and matrix metalloproteinases 2, 7, and 9 at mRNA levels but decreased E-cadherin at mRNA level, indicating that the high invasive and metastatic capabilities of ALDH1A1 ${ }^{\text {high }}$ cells may be achieved by the epithelial-mesenchymal transition (EMT) and secretary matrix metalloproteinases. Therefore, ALDH can be successfully utilized in the selection of EC subpopulation with stem-like properties that capture greater potentiality of being tumorigenic.

\section{Pathways involved in EC stem cells}

The signaling pathways involved in embryogenesis also play a pivotal role in oncogenesis. Some of the important pathways highly involved in the sustentation of ECSCs include Wnt/ $\beta$-catenin, Notch, Hh, and Hippo. These pathways are associated with the balance of tissue homeostasis and normal stem cell renewal. ${ }^{50}$ Any dysregulation of such signaling drives CSC activity in diverse cancer types.

\section{Wnt/ $\beta$-catenin pathway}

The Wnt/ $\beta$-catenin signaling pathway is famous for regulating the generation and oncogenesis in many systems. ${ }^{51}$ In the normal physiological state, the Wnt/ $\beta$-catenin signaling pathway regulates downstream genes involved in basic cellular biological functions, such as cell proliferation, differentiation, apoptosis, and cell death. ${ }^{52}$ Thus, Wnt/ $\beta$-catenin signaling should be kept at the normal level to exert normal physiological function. However, a number of findings have shown that the Wnt/ $\beta$-catenin pathway is constitutively activated in many cancers. The aberrant $\beta$-catenin expression could be an adverse underlying factor of ESCC in cancer progression, metastasis, and invasion. ${ }^{53} \mathrm{Ge}$ et $\mathrm{al}^{54}$ revealed a new mechanism by which miR-942 triggers ESCC stem cell-like traits by activating the $\mathrm{Wnt} / \beta$-catenin pathway. They found that miR-942 induces ESCC stem-like traits by directly targeting secreted frizzled-related protein 4, glycogen synthase kinase 3 beta, and transducin-like enhancer protein 1, which are all vital negative regulators of the Wnt/ $\beta$-catenin pathway. Furthermore, miR-942 was powerfully overexpressed in ESCCs and negatively correlated with EC prognosis, as seen from microRNA screening and real-time polymerase chain reaction assays. In a recent study, several critical stem-cell-related genes, such as Octamer-4 (Oct-4), Frizzled 10 (FZD10), prostaglandin-endoperoxide synthase 2 (PTGS2), and Krüppel-like factor 5 (KLF5), were upregulated in diverse histological subtypes in EC cell lines, as seen from quantitative real-time reverse transcription polymerase chain reaction, which was parallel to the results of Western blot. ${ }^{17}$ Moreover, the expressions of stem cell markers $\beta$-catenin, Oct3/4, and $\beta 1$-integrin were remarkably higher than that of parental cells in EC cells following fractionated irradiation. ${ }^{55}$ In a study involving 136 patients with ESCC, the correlations between Wnt6 expression and survival parameters were analyzed. The results found that Wnt6, considered as a predictor for recurrence, may play a central role in tumor progression and inversely correlate with the poor long-term survival in ESCC patients. ${ }^{56}$

\section{Notch pathway}

The Notch pathway is evolutionarily conserved with a critical role in determining cell fate, such as cell proliferation, 
differentiation, and stem cell maintenance. The Notch family may play an important role in cell differentiation and EMT in tumorigenesis because of its principal functions in CSCs. ${ }^{57} \mathrm{HEY} 1$ and HEY2, which belong to a family of basic helix-loop-helix transcription factors, are two key target genes of the Notch signaling pathway. Forghanifard et $\mathrm{al}^{58}$ sought to explore the activation of the Notch signaling pathway in ESCC through expressional analysis of the signaling target genes. Their results elucidated that HEY1 and HEY2 were significantly overexpressed in association with the clinicopathological features of ESCC patients, confirming that deregulated activation of the Notch signaling pathway plays a role in the development and progression of the malignancy and may be considered in therapeutic modalities to restrict ESCC progression. In another study, the expression of the Notch family in the ESCC lines KYSE70, KYSE140, and KYSE450 and virus-transformed squamous esophageal epithelial cell line Het-1A was evaluated at the mRNA and protein levels in vitro. The overexpression of Notch1 and Notch3 was compared in the above cell lines. In clinical samples, Notch 1 protein expression was tested in the basal cells of human esophagus epithelia and squamous cell carcinomas. The authors reported that overexpression of Notch1 protein in ESCC tissues was significantly associated with advanced histological grade and poor patient survival. In addition, 5-fluorouracil (5-FU) resistance is correlated with Notch1 expression, as verified by Notch1 small interfering RNA experiments. ${ }^{59}$ Nonetheless, Notch signaling appears to be an attractive target for anticancer therapeutic interventions because of its role in stem cell maintenance and tumorigenesis.

\section{Hh signaling}

Although the presence of Hh signaling is almost negligible in adult tissues, it is an important component of embryogenesis and regulates the proliferation, differentiation, and migration of embryonic stem cells. ${ }^{60}$ Activation of Hh signaling by binding secreted $\mathrm{Hh}$ ligands to the membrane receptor results in nuclear translocation and activation of transcription factors of the glioma-associated oncogene (Gli) family, whose targets are composed of genes controlling the cell cycle, cell adhesion, and signal transduction. ${ }^{61} \mathrm{Hh}-\mathrm{Gli}$ signaling has been involved in the maintenance of different cancers, including breast, melanoma, and lung cancers. ${ }^{62-64}$ SimsMourtada et $\mathrm{al}^{65}$ showed that $\mathrm{Hh}$ pathway activity affects the proliferation rates of EC cell lines through upregulation of the G1-cyclin-Rb axis. In addition, they found that blocking Hh signaling enhances radiation sensitivity of EC cells.
These results suggest that activating the Hh pathway may contribute to chemoradiation resistance in EC.

\section{Hippo pathway}

The Hippo signaling pathway is regarded as an important player not only in organ size control but also in tumorigenesis, because the disruption of any important components (mammalian ste20-like kinase [Mst] 1/2, salvador homolog 1 [Sav1] and large tumor suppressor [Lats] 1/2, and YAP-1) in this pathway can lead to tumorigenesis. ${ }^{66}$ YAP-1, the downstream effector of the Hippo signaling pathway, is constantly overexpressed in many cancer types and mediates the constitutive and acquired treatment resistance in EAC cells. ${ }^{21,67}$ Emerging evidence indicates the importance of YAP-1 and deregulation of the Hippo pathway during cancer development and progression. In a clinical research, EAC and ESCC were characterized by a significant increase in YAP-1 in cytoplasmic and nuclear cells. ${ }^{68}$ Recent studies have identified YAP-1 as a major inducer of CSC properties in non-tumorigenic cells and EC cells through direct upregulation of SOX9. Thus, the YAP-1-SOX9 axis can be an important therapeutic target in EC. ${ }^{19}$

\section{Targeting ECSCs for therapy}

ECSCs, as well as local tumor microenvironment, play a significant role in tumor initiation and progression. The signal a cell receives from its microenvironment determines the cell's fate. EC therapy targeted at the CSCs or the tumor microenvironment has been developed accordingly. In recent years, it has been shown that the enrichment of CSCs through transforming growth factor beta 1 (TGF- $\beta 1$ )-mediated EMT in ESCCs can be overcome by using erlotinib and cetuximab, which target CD44, Notch1, and Notch3 by suppressing expression of zinc-finger E-box binding homeobox 1 (ZEB1) and ZEB2, which are known regulators of EMT. Epidermal growth factor receptor inhibitors could be one effective therapeutic strategy targeting against the generation of CSCs in the ESCC microenvironment. ${ }^{69}$ All-trans retinoic acid can also induce ESCC differentiation and dramatically downregulate the expression of CD44 mRNA and protein levels, which is a platform that integrates cellular microenvironmental cues with growth factor and cytokine signals, suggesting a potential application of all-trans retinoic acid differentiation therapy for CD44. ${ }^{27} \mathrm{CXCR} 4$ silenced by small interfering RNA can suppress the proliferation, invasion, and metastasis of EC cell lines KYSE-150 and TE-13 in vitro and in vivo. These results provide a theoretical and experimental basis for the gene therapy of ESCC using RNA interference technology 
based on the CXCR4 target site. ${ }^{39}$ Mithramycin could repress basal- and CSC-mediated induction of ABCG2 and dramatically decrease the prolifand tumorigenicity of EC cells, thereby showing the potential activity for targeting ABCG2 and other stem-cell-related genes in thoracic malignancies. ${ }^{34}$ Metformin, usually used as an oral anti-hyperglycemic agent, may reduce cancer risk and have antitumor effects in many cancer types. The synergy between metformin and 5-FU can potentially treat CSCs and simultaneously increase the sensitivity of chemoradiation in EAC patients through ribosomal S6 kinase (S6K) phosphorylation, and the crosstalk between mTOR and Hh signaling confers tumor cell growth advantage and resistance to therapy. ${ }^{70}$ Others have found that YAP-1 knockdown by lentivirus short hairpin RNA in EC cells decreases tumor cell growth and increases 5-FU sensitivity in EC. These results were consistent with the recent finding of Huang et al, ${ }^{71}$ who reported that YAP-1 knockdown sensitized ovarian cancer cells to cisplatin and survivin inhibitors. Moreover, Verteporfin, a novel YAP-1 inhibitor, effectively inhibits YAP-1 and epidermal growth factor receptor expression and sensitizes the cytotoxic effects of 5-FU or docetaxcel on EC cells. These data demonstrate that YAP-1-targeted modalities are a promising strategy when combined with cytotoxics to achieve maximal therapeutic effects. ${ }^{21}$ ABT-263, a potent Bcl-2 family inhibitor, is active against many tumor types. ABT-263 was reported to sharply suppress the CSC properties by Wnt/ $\beta$-catenin and YAP/SOX9 axes in EC cells. The combination of ABT263 and 5-FU significantly reduces tumor growth in vivo and suppresses the expression of stemness genes. Based on these findings, a novel mechanism of ABT-263 antitumor effect is demonstrated, indicating that combining ABT-263 with cytotoxic drugs is worthy of pursuit in EC patients. ${ }^{72}$ The majority of these studies reported the effectiveness of targeting ECSCs in controlling different EC subtypes.

\section{Conclusion}

EC occurs with high prevalence in different regions of the world, and the high-incidence areas include the People's Republic of China, Iran, South Africa, and France. ${ }^{73}$ EC is the fourth highest cause of cancer-related mortality in the People's Republic of China and seventh in the world. ${ }^{74}$ Surgical resection and neoadjuvant chemotherapy or radiotherapy are the common treatment modalities used nowadays. However, EC is difficult to treat because of its resistance to current standard therapies. CSCs are thought to be the basic cause of tumor formation, metastasis, recurrence, and therapy failure. ${ }^{75-77}$ Therefore, an accurate understanding of ECSC is critical for the comprehension of the biology of esophageal epithelium in health and disease. Different markers and pathways, such as CD44/CD24, CD133, Notch, and $\mathrm{Wnt} / \beta$-catenin, are deregulated in specific cancer cases, even in EC. Thus, their roles need to be elucidated so that these markers and pathways can be targeted to design definitive therapeutic modalities against drug-resistant EC and solve the problem of tumor relapse.

\section{Disclosure}

The authors report no conflicts of interest in this work.

\section{References}

1. Shiguro S, Sasazuki S, Inoue M, et al; JPHC Study Group. Effect of alcohol consumption, cigarette smoking and flushing response on esophageal cancer risk: a population-based cohort study (JPHC study). Cancer Lett. 2009;275(2):240-246.

2. Li JC, Liu D, Yang Y, et al. Growth, clonability, and radiation resistance of esophageal carcinoma-derived stem-like cells. Asian Pac J Cancer Prev. 2013;14(8):4891-4896.

3. Pennathur A, Gibson MK, Jobe BA, Luketich JD. Oesophageal carcinoma. Lancet. 2013;381(9864):400-412.

4. Crosby TD, Evans M. Resectable oesophageal cancer: a practice guideline update. Practice changing or supporting the status quo? Clin Oncol (R Coll Radiol). 2010;22(4):247-249.

5. Clarke MF, Dick JE, Dirks PB, et al. Cancer stem cells - perspectives on current status and future directions: AACR Workshop on cancer stem cells. Cancer Res. 2006;66(19):9339-9344.

6. Dalerba P, Cho RW, Clarke MF. Cancer stem cells: models and concepts. Аnпи Rev Med. 2007;58:267-284.

7. D'Angelo RC, Wicha MS. Stem cells in normal development and cancer. Prog Mol Biol Transl Sci. 2010;95:113-158.

8. She JJ, Zhang PG, Wang X, Che XM, Wang ZM. Side population cells isolated from KATO III human gastric cancer cell line have cancer stem celllike characteristics. World J Gastroenterol. 2012;18(33):4610-4617.

9. Diehn M, Clarke MF. Cancer stem cells and radiotherapy: new insights into tumor radioresistance. $J$ Natl Cancer Inst. 2006;98(24): 1755-1757.

10. Alison MR, Lin WR, Lim SM, Nicholson LJ. Cancer stem cells: in the line of fire. Cancer Treat Rev. 2012;38(6):589-598.

11. Bonnet D, Dick JE. Human acute myeloid leukemia is organized as a hierarchy that originates from a primitive hematopoietic cell. Nat Med. 1997; 3(7):730-737.

12. Prince ME, Sivanandan R, Kaczorowski A, et al. Identification of a subpopulation of cells with cancer stem cell properties in head and neck squamous cell carcinoma. Proc Natl Acad Sci U S A. 2007;104(3): 973-978.

13. Al-Hajj M, Wicha MS, Benito-Hernandez A, Morrison SJ, Clarke MF. Prospective identification of tumorigenic breast cancer cells. Proc Natl Acad Sci U S A. 2003;100(7):3983-3988.

14. Ricci-Vitiani L, Lombardi DG, Pilozzi E, et al. Identification and expansion of human colon-cancer-initiating cells. Nature. 2007;445(7123): 111-115.

15. Collins AT, Berry PA, Hyde C, Stower MJ, Maitland NJ. Prospective identification of tumorigenic prostate cancer stem cells. Cancer Res. 2005;65(23):10946-10951.

16. Huang D, Gao Q, Guo L, et al. Isolation and identification of cancer stem-like cells in esophageal carcinoma cell lines. Stem Cells Dev. 2009; 18(3):465-473.

17. Chen CL, Tsukamoto H, Liu JC, et al. Reciprocal regulation by TLR4 and TGF-beta in tumor-initiating stem-like cells. J Clin Invest. 2013;123(7):2832-2849. 
18. Song S, Ajani JA, Honjo S, et al. Hippo coactivator YAP1 upregulates SOX9 and endows esophageal cancer cells with stem-like properties. Cancer Res. 2014;74(15):4170-4182.

19. Song S, Honjo S, Jin J, et al. The hippo coactivator YAP1 mediates EGFR overexpression and confers chemoresistance in esophageal cancer. Clin Cancer Res. 2015;21(11):2580-2590.

20. Okumura T, Tsunoda S, Mori Y, et al. The biological role of the low-affinity p75 neurotrophin receptor in esophageal squamous cell carcinoma. Clin Cancer Res. 2006;12(17):5096-5103.

21. Tang KH, Dai YD, Tong M, et al. A CD90(+) tumor-initiating cell population with an aggressive signature and metastatic capacity in esophageal cancer. Cancer Res. 2013;73(7):2322-2332.

22. Croagh D, Phillips WA, Redvers R, Thomas RJ, Kaur P. Identification of candidate murine esophageal stem cells using a combination of cell kinetic studies and cell surface markers. Stem Cells. 2007;25(2):313-318.

23. Huang ZL, Lin ZR, Xiao YR, et al. High expression of TACC3 in esophageal squamous cell carcinoma correlates with poor prognosis. Oncotarget. 2015;6(9):6850-6861.

24. Von Rahden BH, Kircher S, Lazariotou M, et al. LgR5 expression and cancer stem cell hypothesis: clue to define the true origin of esophageal adenocarcinomas with and without Barrett's esophagus? J Exp Clin Cancer Res. 2011;30:23.

25. Meng X, Li M, Wang X, Wang Y, Ma D. Both CD133+ and CD133subpopulations of A549 and H446 cells contain cancer-initiating cells Cancer Sci. 2009;100(6):1040-1046.

26. Rassouli FB, Matin MM, Bahrami AR, et al. Evaluating stem and cancerous biomarkers in CD15+CD44+ KYSE30 cells. Tumour Biol. 2013;34(5):2909-2920.

27. Lee HJ, Choe G, Jheon S, Sung SW, Lee CT, Chung JH. CD24, a novel cancer biomarker, predicting disease-free survival of non-small cell lung carcinomas: a retrospective study of prognostic factor analysis from the viewpoint of forthcoming (seventh) new TNM classification. J Thorac Oncol. 2010;5(5):649-657.

28. Almanaa TN, Geusz ME, Jamasbi RJ. A new method for identifying stem-like cells in esophageal cancer cell lines. J Cancer. 2013;4(7): 536-548.

29. Smit JK, Faber H, Niemantsverdriet M, et al. Prediction of response to radiotherapy in the treatment of esophageal cancer using stem cell markers. Radiother Oncol. 2013;107(3):434-441.

30. Tsai ST, Wang PJ, Liou NJ, Lin PS, Chen CH, Chang WC. ICAM1 is a potential cancer stem cell marker of esophageal squamous cell carcinoma. PLoS One. 2015;10(11):e0142834.

31. Honing J, Pavlov KV, Mul VE, et al. CD44, SHH and SOX2 as novel biomarkers in esophageal cancer patients treated with neoadjuvant chemoradiotherapy. Radiother Oncol. 2015;117(1):152-158.

32. Ding XW, Wu JH, Jiang CP. ABCG2: a potential marker of stem cells and novel target in stem cell and cancer therapy. Life Sci. 2010; 86(17-18):631-637.

33. Huang L, Lu Q, Han Y, Li Z, Zhang Z, Li X. ABCG2/V-ATPase was associated with the drug resistance and tumor metastasis of esophageal squamous cancer cells. Diagn Pathol. 2012;7:180.

34. Zhang M, Mathur A, Zhang Y, et al. Mithramycin represses basal and cigarette smoke-induced expression of ABCG2 and inhibits stem cell signaling in lung and esophageal cancer cells. Cancer Res. 2012 72(16):4178-4192.

35. Tirino V, Camerlingo R, Franco R, et al. The role of CD133 in the identification and characterisation of tumour-initiating cells in non-small-cell lung cancer. Eur J Cardiothorac Surg. 2009;36(3):446-453.

36. Zhang DG, Jiang AG, Lu HY, Zhang LX, Gao XY. Isolation, cultivation and identification of human lung adenocarcinoma stem cells. Oncol Lett. 2015;9(1):47-54.

37. Okamoto H, Fujishima F, Nakamura Y, et al. Significance of CD133 expression in esophageal squamous cell carcinoma. World J Surg Oncol. 2013;11:51.

38. Lu CL, Guo J, Gu J, et al. CXCR4 heterogeneous expression in esophageal squamous cell cancer and stronger metastatic potential with CXCR4-positive cancer cells. Dis Esophagus. 2014;27(3):294-302.
39. Wang T, Mi Y, Pian L, et al. RNAi targeting CXCR4 inhibits proliferation and invasion of esophageal carcinoma cells. Diagn Pathol. 2013;8:104.

40. $\mathrm{Lu} \mathrm{C}, \mathrm{Xu} \mathrm{F}, \mathrm{Gu}$ J, et al. Clinical and biological significance of stem-like CD133(+)CXCR4(+) cells in esophageal squamous cell carcinoma. J Thorac Cardiovasc Surg. 2015;150(2):386-395.

41. Hang D, Dong HC, Ning T, Dong B, Hou DL, Xu WG. Prognostic value of the stem cell markers CD133 and ABCG2 expression in esophageal squamous cell carcinoma. Dis Esophagus. 2012;25(7):638-644.

42. Hess DA, Craft TP, Wirthlin L, et al. Widespread nonhematopoietic tissue distribution by transplanted human progenitor cells with high aldehyde dehydrogenase activity. Stem Cells. 2008;26(3):611-620.

43. Storms RW, Trujillo AP, Springer JB, et al. Isolation of primitive human hematopoietic progenitors on the basis of aldehyde dehydrogenase activity. Proc Natl Acad Sci U S A. 1999;96(16):9118-9123.

44. Huang CP, Tsai MF, Chang TH, et al. ALDH-positive lung cancer stem cells confer resistance to epidermal growth factor receptor tyrosine kinase inhibitors. Cancer Lett. 2013;328(1):144-151.

45. Jiang F, Qiu Q, Khanna A, et al. Aldehyde dehydrogenase 1 is a tumor stem cell-associated marker in lung cancer. Mol Cancer Res. 2009;7(3): $330-338$.

46. Wang Y, Zhe H, Gao P, Zhang N, Li G, Qin J. Cancer stem cell marker ALDH1 expression is associated with lymph node metastasis and poor survival in esophageal squamous cell carcinoma: a study from high incidence area of northern China. Dis Esophagus. 2012;25(6): 560-565.

47. Zhang G, Ma L, Xie YK, Miao XB, Jin C. Esophageal cancer tumorspheres involve cancer stem-like populations with elevated aldehyde dehydrogenase enzymatic activity. Mol Med Rep. 2012;6(3):519-524.

48. Fujiwara D, Kato K, Nohara S, Iwanuma Y, Kajiyama Y. The usefulness of three-dimensional cell culture in induction of cancer stem cells from esophageal squamous cell carcinoma cell lines. Biochem Biophys Res Commun. 2013;434(4):773-778.

49. Yang L, Ren Y, Yu X, et al. ALDH1A1 defines invasive cancer stem-like cells and predicts poor prognosis in patients with esophageal squamous cell carcinoma. Mod Pathol. 2014;27(5):775-783.

50. Lu Y, Thomson JM, Wong HY, Hammond SM, Hogan BL. Transgenic over-expression of the microRNA miR-17-92 cluster promotes proliferation and inhibits differentiation of lung epithelial progenitor cells Dev Biol. 2007;310(2):442-453.

51. Katoh M. WNT signaling pathway and stem cell signaling network. Clin Cancer Res. 2007;13(14):4042-4045.

52. Robinson JA, Chatterjee-Kishore M, Yaworsky PJ, et al. Wnt/betacatenin signaling is a normal physiological response to mechanical loading in bone. J Biol Chem. 2006;281(42):31720-31728.

53. Marson A, Foreman R, Chevalier B, et al. Wnt signaling promotes reprogramming of somatic cells to pluripotency. Cell Stem Cell. 2008; 3(2):132-135

54. Ge C, Wu S, Wang W, et al. miR-942 promotes cancer stem cell-like traits in esophageal squamous cell carcinoma through activation of Wnt/betacatenin signalling pathway. Oncotarget. 2015;6(13):10964-10977.

55. Zhang X, Komaki R, Wang L, Fang B, Chang JY. Treatment of radioresistant stem-like esophageal cancer cells by an apoptotic gene-armed, telomerase-specific oncolytic adenovirus. Clin Cancer Res. 2008;14(9): 2813-2823.

56. Zhang L, Yuan G, Fang Y, et al. Increased WNT6 expression in tumor cells predicts unfavorable survival in esophageal squamous cell carcinoma patients. Int J Clin Exp Pathol. 2015;8(9):11421-11427.

57. Wang Z, Li Y, Kong D, Sarkar FH. The role of Notch signaling pathway in epithelial-mesenchymal transition (EMT) during development and tumor aggressiveness. Curr Drug Targets. 2010;11(6):745-751.

58. Forghanifard MM, Taleb S, Abbaszadegan MR. Notch signaling target genes are directly correlated to esophageal squamous cell carcinoma tumorigenesis. Pathol Oncol Res. 2015;21(2):463-467.

59. Liu J, Fan H, Ma Y, et al. Notch1 is a 5-fluorouracil resistant and poor survival marker in human esophagus squamous cell carcinomas. PLoS One. 2013;8(2):e56141. 
60. Varjosalo M, Taipale J. Hedgehog: functions and mechanisms. Genes Dev. 2008;22(18):2454-2472.

61. Ruel L, Rodriguez R, Gallet A, Lavenant-Staccini L, Thérond PP. Stability and association of smoothened, Costal2 and fused with cubitus interruptus are regulated by hedgehog. Nat Cell Biol. 2003;5(10): 907-913.

62. Peacock CD, Wang Q, Gesell GS, et al. Hedgehog signaling maintains a tumor stem cell compartment in multiple myeloma. Proc Natl Acad Sci U S A. 2007;104(10):4048-4053.

63. Mukherjee S, Frolova N, Sadlonova A, et al. Hedgehog signaling and response to cyclopamine differ in epithelial and stromal cells in benign breast and breast cancer. Cancer Biol Ther. 2006;5(6):674-683.

64. Yuan Z, Goetz JA, Singh S, et al. Frequent requirement of hedgehog signaling in non-small cell lung carcinoma. Oncogene. 2007;26(7): 1046-1055

65. Sims-Mourtada J, Izzo JG, Ajani J, Chao KS. Sonic Hedgehog promotes multiple drug resistance by regulation of drug transport. Oncogene. 2007;26(38):5674-5679.

66. $\mathrm{Lu} \mathrm{L}, \mathrm{Li} \mathrm{Y}, \mathrm{Kim} \mathrm{SM}$, et al. Hippo signaling is a potent in vivo growth and tumor suppressor pathway in the mammalian liver. Proc Natl Acad Sci U S A. 2010;107(4):1437-1442.

67. Mao B, Hu F, Cheng J, et al. SIRT1 regulates YAP2-mediated cell proliferation and chemoresistance in hepatocellular carcinoma. Oncogene. 2014;33(11):1468-1474.

68. Muramatsu T, Imoto I, Matsui T, et al. YAP is a candidate oncogene for esophageal squamous cell carcinoma. Carcinogenesis. 2011;32(3): 389-398.
69. Sato F, Kubota Y, Natsuizaka M, et al. EGFR inhibitors prevent induction of cancer stem-like cells in esophageal squamous cell carcinoma by suppressing epithelial-mesenchymal transition. Cancer Biol Ther. 2015;16(6):933-940.

70. Wang Y, Ding Q, Yen CJ, et al. The crosstalk of mTOR/S6K1 and Hedgehog pathways. Cancer Cell. 2012;21(3):374-387.

71. Huang JM, Nagatomo I, Suzuki E, et al. YAP modifies cancer cell sensitivity to EGFR and survivin inhibitors and is negatively regulated by the non-receptor type protein tyrosine phosphatase 14. Oncogene. 2013; 32(17):2220-2229.

72. Chen Q, Song S, Wei S, et al. ABT-263 induces apoptosis and synergizes with chemotherapy by targeting stemness pathways in esophageal cancer. Oncotarget. 2015;6(28):25883-25896.

73. Parking DM, Laara E, Muir CS. Estimates of the worldwide frequency of sixteen major cancers in 1980. Int J Cancer. 1988;41:184-197.

74. Parkin DM, Bray F, Ferlay J, Pisani P. Global cancer statistics, 2002. CA Cancer J Clin. 2005;55(2):74-108.

75. Filipovic A, Stebbing J, Giamas G. Cancer stem cells - therapeutic targeting or therapy? Lancet Oncol. 2013;14(7):579-580.

76. Butof R, Dubrovska A, Baumann M. Clinical perspectives of cancer stem cell research in radiation oncology. Radiother Oncol. 2013; 108(3):388-396.

77. Peitzsch C, Kurth I, Kunz-Schughart L, Baumann M, Dubrovska A. Discovery of the cancer stem cell related determinants of radioresistance. Radiother Oncol. 2013;108(3):378-387.
OncoTargets and Therapy

\section{Publish your work in this journal}

OncoTargets and Therapy is an international, peer-reviewed, open access journal focusing on the pathological basis of all cancers, potential targets for therapy and treatment protocols employed to improve the management of cancer patients. The journal also focuses on the impact of management programs and new therapeutic agents and protocols on

\section{Dovepress}

patient perspectives such as quality of life, adherence and satisfaction The manuscript management system is completely online and includes a very quick and fair peer-review system, which is all easy to use. Visit http://www.dovepress.com/testimonials.php to read real quotes from published authors. 